\title{
A RELAÇÃO MÃE-BEBÊ NA PSICANÁLISE: UM BREVE ESTUDO TEÓRICO
}

DOI: $10.22289 / 2446-922 X . V 3 N 2 A 8$

\author{
Vanessa Gomes da Silva ${ }^{1}$ \\ Karla Priscilla Lemgruber
}

\section{RESUMO}

Nos anos iniciais, a relação mãe-bebê é de fundamental importância no processo de formação da psique humana. Vários estudiosos e psicanalistas tais como Klein, Bion, Winnicott e Bick têm pesquisado a relação mãe-bebê, seu impacto benéfico, suas falhas e as consequências destas na construção do aparelho psíquico. Embora em diferentes abordagens e conceitos, há um consenso entre os estudiosos aqui apresentados no que tange à importância dessa relação inicial para o desenvolvimento mental do indivíduo. Partindo dessa convergência entre os autores citados é que o presente trabalho aborda suas contribuições e o Método Bick de Observação de Bebês. Esther Bick, apoiada em Klein e Bion, criou o método com fins didáticos e atualmente é utilizado como meio de encontrar as falhas na relação inicial da mãe com o bebê, possibilitando a intervenção psicanalítica.

Palavras-chave: Mãe-bebê; Método Bick; Relação inicial; Intervenção

\section{ABSTRACT}

In the early years, the mother-baby relationship has fundamental importance in the human psyche's forming process. Several scholars and psychoanalysts such as Klein, Bion, Winnicott and Bick have researched the mother-baby relationship, and its beneficial impact, its failures and the consequences of these in the construction of the psychic apparatus. Although in different approaches and concepts, there is a consensus among scholars presented here regarding the importance of this initial relationship to the individual's mental development. Based on this convergence between the authors mentioned, is that the present work will approach the Bick Method of Observation of Infants. Esther Bick, based on Klein and Bion, created the method for didactic purposes and is currently used as a means of finding the flaws in the mother's- baby initial relationship, enabling psychoanalytic intervention.

Keywords: Mother-baby; Bick method; Initial relation; Intervention.

\footnotetext{
${ }^{1}$ Endereço eletrônico de contato: vanessagomes725@yahoo.com.br

Recebido em 22/09/2017. Aprovado pelo Conselho Editorial e aceito para publicação em 13/10/2017.
}

Rev. Psicol Saúde e Debate. Dez., 2017:3(2):90-102. 


\section{INTRODUÇÃO}

Com base em diferentes estudos sobre a natureza dos processos psíquicos, os teóricos da psicanálise, cujas contribuições foram usadas no presente estudo, (Freud, Klein, Bowlby Winnicott, Bion e Bick), concluíram de maneira análoga que a personalidade do indivíduo é formada e permanentemente fixada na primeira infância, sendo de grande importância a interação mãe-bebê no primeiro ano de vida para a formação do aparelho psíquico saudável na criança (Bowlby, 2001)

Perceber esse processo psíquico e suas consequências na saúde mental é primordial para o adequado diagnóstico de neuroses ou outros distúrbios psíquicos que se apresentem mais tarde (Bick, 1988). Para tal é necessário um profundo conhecimento dos processos interativos mãe-bebê, suas razões, ausência, presença e desdobramentos. Conhecer as teorias existentes sobre os efeitos da interação seja ela boa ou não, permite ao estudante e futuro psicoterapeuta identificar suas manifestações, bem como provê-lo de ferramentas para diagnóstico e tratamento (Bowlby, 2001).

Baseado nas contribuições de autores e psicanalistas que estudaram a díade mãebebê, e sua complexidade através da personalidade, afeto, vínculo, emoções e patologias, o presente trabalho de pesquisa bibliográfica pretende apresentar as teorias de alguns autores (Klein, Winnicott, Bion), bem como o Método de Observação de Bebês de Esther Bick e as contribuições de Marisa Mélega, buscando-se uma compreensão dos principais conceitos e aspectos para entendimento do assunto.

O trabalho tem como objetivo conhecer a relação mãe-bebê na visão dos autores citados e abordar o método de observação de bebês de Esther Bick, que para ser alcançado exige um conhecimento mínimo de alguns conceitos de psicanalistas clássicos como Klein, Winnicott e Bion. Por isso uma inicial apresentação desses autores será realizada. Trata-se de um conciso estudo teórico sobre o método de observação da relação mãe-bebê com a apresentação de conceitos básicos que dão sustentação ao método.

\section{METODOLOGIA}

O presente trabalho é de natureza exploratória utilizando a metodologia qualitativa como abordagem dos dados. O instrumento utilizado é a pesquisa bibliográfica, elaborada através de uma revisão de literatura sistemática a partir de material já publicado, constituído 
principalmente de livros e artigos disponibilizados na Internet para levantamento do estado da arte, a fundamentação teórica e justificar os limites e contribuições da própria pesquisa.

A metodologia qualitativa busca essencialmente o conhecimento que é resultante do processo de construção interpretativa que dará sentido àquilo que se colheu de dados do objeto de estudo, no caso, a relação mãe-bebê dentro da ótica psicanalítica. Assim, buscouse entre livros, revistas, artigos acadêmicos, sites e revistas eletrônicas, o que há de disponível sobre o tema, abordado no período entre 2007 e 2017, através dos seguintes descritores: relação mãe-bebê, anos iniciais do bebê, a mãe suficientemente boa, projeçãointrojeção, método Bick, dentre outros suficientes para dar embasamento à presente pesquisa.

Em seguida, são aqui apresentados os dados e resultados obtidos no decurso da investigação, bem como a conclusão a que se chegou, já que é a relação investigador-objeto de estudo, condição para o desenvolvimento da pesquisa exploratória (Martins, 2004).

\section{FUNDAMENTAÇÃO TEÓRICA}

\section{A RELAÇÃO MÃE BEBÊ EM KLEIN, WINNICOTT E BION}

O novo conceito Freudiano da infância, traz a criança como um sujeito desejante, exigindo amor e a satisfação de suas necessidades. A criança é introduzida na elaboração psicanalítica através do relato das histéricas sobre abusos, em que a maior parte destas afirmava ter sido objeto de desejo do pai, ou substituto, tendo seus corpos manuseados de modo a sugerir uma atração anormal - relatos sobre os quais posteriormente se concluiu serem reminiscências de desejos que se tornaram inconscientes (Freud, 1905).

Através da teoria do Complexo de Édipo ${ }^{1}$, Sigismund Schlomo Freud, mais conhecido como Sigmund Freud (1856-1939), médico austríaco considerado o Pai da Psicanálise, descobriu não apenas a sexualidade infantil, mas também o inconsciente reprimido - ponto de onde partem os conflitos que causam neuroses e por onde tratá-las. A partir desta teoria Freud formulou outra: a teoria psicanalítica. O complexo de Édipo, bem como o mito de Édipo

\footnotetext{
${ }^{1} \mathrm{O}$ termo Complexo de Édipo criado por Freud e inspirado na tragédia grega Édipo Rei designa o conjunto de desejos amorosos e hostis que o menino enquanto ainda criança experimenta com relação a sua mãe. O fenômeno psíquico também ocorre nas meninas com relação ao pai, mas a este se dá o nome de Complexo de Electra. A partir da auto repressão de tais sentimentos, surge o inconsciente reprimido - fonte de neuroses.
}

Rev. Psicol Saúde e Debate. Dez., 2017:3(2):90-102. 
e a sua versão em Sófocles, serviram a Freud de 'instrumento para descobrir a psicanálise'. Sendo assim conhecida a psicanálise freudiana como 'edipiana'. (Freud, 1938).

A partir das teorias freudianas sobre os primeiros anos de vida e a relação destes com os pais, vários outros seguidores também estudaram a influência desses primeiros anos de vida com especial ênfase na relação inicial da mãe com o filho. O presente trabalho delimitará apenas as contribuições de Melanie Klein, Donald Winnicott e Wilfred Bion como base para melhor compreensão da relação mãe-bebê, bem como o método Bick de observação de bebês.

Melanie Klein, (1882-1960), psicanalista austríaca, foi declarada seguidora dos ensinamentos de Freud embora se ressentisse do pouco interesse do mestre pela psicanálise infantil, à qual Klein dedicou seu campo de estudos segundo Neves, (2007). Mais tarde, desvinculou-se da teoria freudiana, buscando ir além do complexo de édipo com a teoria do complexo de édipo precoce onde a autora introduz em seus escritos a ideia de que o complexo ocorria muito antes do que Freud o postulou. Inicialmente, o localizou por volta dos 2 ou 3 anos de idade. Klein teorizou sobre a importância da díade mãe-bebê em seus estudos sobre o conceito dos mecanismos de introjeção e projeção como atuantes desde o início da vida psíquica em bebês, entre outros (Klein, 1936).

Para Klein apud Himshelwood (1992) é o elo que liga mãe-bebê e para a psicanalista existem duas posições ou duas formas de constituição da subjetividade que podem ser denominadas de posição esquizo-paranoide e posição depressiva (Klein, 1952).

A posição esquizo-paranoide se inicia no nascimento e perdura até os seis meses de idade onde são os processos de introjeção e projeção que determinam o desenvolvimento da subjetividade. $O$ conceito de seio amado (bom) - aquele que a criança possui e seio odiado (mau) - aquele que se ausenta - caracterizam a primeira relação objetal do bebê. É considerado esse período neonato como o apogeu dos impulsos destrutivos, da angústia persecutória e dos processos de divisão, onipotência, idealização, negação e controle dos objetos internos e externos (Klein, 1930).

O objeto mau é projetado para fora do bebê como sendo perseguidor e destruidor do objeto bom. Nessa fase vemos a existência de uma angústia persecutória, então a meta da criança nessa fase é de possuir o objeto bom e introjetá-lo e também de projetar o objeto mau para fora e assim evitar os impulsos destrutivos (Klein, 1930).

Para Klein, o estado simbiótico inicial é normal, e o bom desenvolvimento do vínculo mãe-bebê, consiste na separação gradual do elo inicial. No entanto, quando os impulsos agressivos e de ansiedade são intensos, as tentativas de desfazer o sofrimento, fixam um 
círculo vicioso que leva à assimilação projetiva patológica (Feliciano, 2009) que será tratada adiante.

Ainda de acordo com Feliciano (2009), na psicanálise Kleiniana, a formação dos símbolos traz o discernimento do bebê entre o eu e o outro. Para Klein a emoção é a [...] 'base da vida mental, aquilo que Ihe dá significado e que existe tanto no consciente como no inconsciente'1, a partir do momento em que se realiza, a experiência emocional provoca a modificação de tudo o que há de recente na mente, e esta sofre com as impressões dos impulsos sobre o ego desde o nascimento, sinalizando para atividade psíquica precoce (Neves, 2007).

Por volta dos seis meses de idade a relação do bebê com a mãe se modifica, bem como toda a realidade externa. O bebê vê a mãe como um ser distinto, separado de si, independente e fonte de experiências boas e más. A criança compreende ainda de maneira rudimentar e paulatinamente que ela é quem ama e odeia esse seio único, sua mãe, e assim surge a experiência do chamado sentimento de ambivalência, onde o bebê começa a ter uma noção de que aquilo que antes temia - a destruição do objeto por perseguidores - pode tornarse ele próprio agente dessa destruição do objeto amado e odiado. Sua angústia deixa de ser paranoide e torna-se depressiva, dando origem aos sentimentos de culpa e luto (Feliciano, 2009).

Já Donald. W. Winnicott, (1896-1971), pediatra e psicanalista inglês, acreditava que nem todas as formas de distúrbio se relacionavam ao conflito do complexo de Édipo plenamente desenvolvido. Para ele, algo estava errado em algum ponto anterior (Coutinho, 1997).

Winnicott trata do desenvolvimento emocional próprio da fase da lactação, antes da relação triangular, ou seja, no período em que a criança é capaz de criar vínculo com apenas um outro - a mãe.

Ainda, segundo Winnicott, é durante os últimos meses de gestação e primeiras semanas posteriores ao parto, que surge na mãe um estado psicológico distinto a que o autor nomeou de "preocupação materna primaria", cuja característica é a exacerbada capacidade da mãe em desenvolver empatia com o filho, colocando-se em seu lugar e sentindo suas necessidades. Para Winnicott é somente no estado de preocupação primária que a mãe vai fornecer um ambiente facilitador para o bebê se desenvolver, tornando as suas necessidades básicas em necessidades do ego (Winnicott, 1951).

\footnotetext{
1 J. psicanal. vol.44 no.81 São Paulo dez. 2011
} 
Winnicott trata do desenvolvimento emocional próprio da fase de lactação, antes da relação triangular, ou seja, no período em que a criança é capaz de formar um relacionamento apenas com um outro (a mãe). Supõe-se um desenvolvimento anterior bem-sucedido, onde o self é sentido cada vez mais como uma unidade, dando à criança ideia de um eu e um nãoeu.

Através do holding materno, quando a mãe segura adequadamente o bebê, a mãe propicia ao bebê sair do estágio de não integração, onde seu corpo e sua pisque não estão ligados, para o de integração espaço-temporal onde este começa a se instituir como uma unidade. Já a integração psicossomática (a ligação corpo psique) se dá através do handling, ou seja, os cuidados da mãe, é que ele começa a perceber a si mesmo, seu corpo, seus limites, como um ser separado e distinto da mãe e nessa fase, o seio, então, é visto como parte de uma pessoa diferente do bebê, e é essa experiência que o capacita a "[...] começar a existir" (p. 404), a ter experiências, a constituir um ego pessoal, a dominar os instintos e a defrontar-se com as dificuldades inerentes à vida (Winnicott, 2000).

Neste processo, a mãe vai apresentando o mundo ao bebê paulatinamente, aos poucos, de acordo com sua capacidade de relacionar-se com os objetos. Este relacionamento é um processo que segue uma linha evolutiva desde o nascimento até a morte, onde indivíduo vai aumentando o seu círculo de relacionamentos, com a família, depois a escola e finalmente com a sociedade (Winnicott, 1990).

Revolucionário, Winnicott afirmou que uma mãe saudável é uma mãe suficientemente boa, que responde à onipotência do lactante e, de certo modo, dá-lhe sentido, que possibilita ao bebê a fantasia de que o mundo é criação sua, permitindo-lhe experimentar a onipotência primária. A mãe boa é aquela que falha e não se recrimina ou se inferioriza por isso. Essas falhas têm grande importância no desenvolvimento do bebê, pois é através destas que a criança se frustra e começa a entender a si mesmo como ser separado, distinto da mãe (Coutinho, 1997).

Wilfred Bion, psicanalista, cujo conceito de rêverie materna, será muito útil ao trabalho de Bick, é considerado um meio termo entre Klein e Winnicott, dentro do vínculo da díade mãe-bebê elaborou o conceito de continente-conteúdo no contexto da relação, onde o gesto emitido pelo bebê (conteúdo) é vivenciando e interpretado pela mãe (continente). Seu conceito de rêverie materna viria a ser muito útil ao trabalho de Bick (Santos, 2014).

Rêverie é um estado de consciência receptiva e que se mantém através de determinada atividade psíquica. Bion usou o termo pela primeira vez em 1959 afirmando que o paciente psicótico não tem capacidade de rêverie (Parson, 2007). 
A expressão havia sido usada por Max Scheler em 1923 e em sua melhor tradução é uma capacidade materna de determinar as próprias manifestações, de maneira espontânea, de modo a atender as manifestações da vida emocional do bebê. Através da nutrição e expressões, esta consegue estabelecer uma ponte entre o mundo interno e o mundo externo.

Rêverie é então o conceito chave que destaca e ilumina a relação de objeto sendo em si um mistério que desafia a compreensão. Este é um conceito forte na obra de Bion, para quem O rêverie é:

[...] uma função seletiva e especializada da função alfa materna no vínculo com o bebê. Sua função é transformadora ao metabolizar, desintoxicar e acolher a descarga emocional das identificações projetivas do bebê e da própria mãe. É também um sistema completo, que filtra e separa os elementos alfa dos beta, retém os elementos alfa e descarta os beta não transformados. Uma alfa-betização emocional é impulsionada. Ela sustenta a aprendizagem. Esta contribuição de Bion permite conjeturar que, em muitos pacientes que apresentam um diagnóstico de Transtornos Globais no Desenvolvimento Emocional, o retardo e o atraso mental podem ser consequência do déficit na formação do aparato para pensar os pensamentos. Entre os infinitos fatores convocados, destaco as falhas na função materna para poder metabolizar, transformar e digerir os conteúdos do filho (Lisondo, 2010 p. 71).

O rêverie, como atitude receptiva da função materna, é capaz de acolher aquilo que o bebê deseja transmitir. Quando acontece, esta função é capaz de estabelecer relações e vínculos dentro da matriz de significados criando novos significados.

O desenvolvimento da criança acontece através das experiências repetidas das projeções de seus conteúdos para dentro da mãe, os quais são elaborados e transformados na experiência emocional inicial insuportável para uma mais assimilável através do qual o bebê vai constituindo um núcleo do objeto bom que se tornará a base para um ego integrado que torna as experiências antes inaceitáveis em suportáveis - a rêverie materna (Bion, 1994).

O bebê projeta suas agonias em sua mãe, e esta ao aceitar tal angustia, fará o possível para atenuar o sofrimento fazendo com que a percepção do bebê seja a de ter projetado o intolerável dentro do objeto e que este foi capaz de contê-lo e de enfrentá-lo. Este então reintrojeta esta angústia modificada e 'apaziguada'.

A partir dos conceitos de Klein, Wilfred Ruprecht Bion, (1897-1979), psicanalista britânico desenvolve o conceito de rêverie materna e função alfa. Bion aborda a importância das primeiras experiências de relação e vínculo na díade mãe-bebê para o ajustamento narcísico, contenção, pacificação e transformação da violência pulsional primitiva e das angústias precoces que, se não acolhidas e metabolizadas, conduzirão a criança a um incremento dos mecanismos de projeção e violência (Bion 1994).

Rev. Psicol Saúde e Debate. Dez., 2017:3(2):90-102. 
Bion introduz os conceitos de continente/conteúdo e de função alfa - função materna de acolher e conferir significados a estes estados emocionais iniciais do bebê. Esta função foi designada como "capacidade de rêverie". Neste estado, a mente materna, atua como catalisadora dos estados emocionais "violentos" transformando-os em estados emocionais toleráveis, que podem então ser reintrojetados pelo bebê (Santos, 2014).

Para Bion esta é também de suma importância, visto que a estabilidade psíquica pode ficar comprometida caso a mãe não consiga oferecer a rêverie e o significado da experiência ao filho. O bebê por sua vez pode pensar que não há significado, que este não existe e assim, perpetuar o estado de terror diante do desconhecido ou nameless dread (terror sem nome) assim denominado por Karin Stephens, psicanalista inglesa, (1941) para designar o terror impotente da criança diante de seus instintos aterrorizantes e a violência fundamental (Monroe, 1946).

Bion acreditava que o ser humano necessita de outro ser humano para a passagem do estado não mente para o estado de mente e considera que a função de continente para o bebê é um dos elementos para desenvolver o pensar e desenvolver-se de maneira sadia, dessa forma o ambiente é muito importante ao lado das funções internas do bebê. Falhas na rêverie materna fazem com que a criança além de não se sentir gratificada, experimente forte angústia ao receber de volta o que projetara acrescido das angústias da mãe, assim, a interação com seu primeiro objeto será determinante na constituição psíquica, e falhas na função podem acarretar danos emocionais futuros (Monroe, 1946).

\section{O MÉTODO BICK DE OBSERVAÇÃO DE BEBÊS}

A psicanálise trata os primeiros vínculos mãe-bebê como a base estrutural das relações afetivas futuras. Dentro dessa ótica psicanalítica, Esther Bick, (1901-1983), psicanalista polonesa, desenvolveu o método de observação da relação mãe-bebê.

O método Bick de observação, foi criado, em 1948, num esforço para acompanhar e observar a relação mãe-bebê. O objetivo era que os estudantes tivessem uma experiência prática com bebês em sua formação clínica. (Bick, [1964] 2002). Desde a sua criação o método tem sido um instrumento de aprendizagem, de pesquisa e clínica. É considerado ferramenta de aprendizagem porque proporciona ao estudante acompanhar a relação do bebê com os familiares - principalmente com a mãe (Menegotto, 2002).

O método ainda ajuda o clínico a desenvolver atitudes que são fundamentais na prática clínica: receptividade, holding, sensibilidade para a comunicação infantil, entre outras. Bick considerava que a observação de um bebê com sua mãe, proporciona ao observador 
uma experiência importante permitindo o acesso deste a um estágio de vida primitivo, trazendo maior compreensão da criança e sua mãe durante o tratamento de crianças (Menegotto, 2002).

Segundo Bick (1988) as primeiras experiências emocionais são sentidas primariamente pelo corpo. Inicialmente, o bebê necessita que as partes de sua personalidade sejam mantidas unidas por um objeto externo que seja continente. Bick deu a esse mecanismo o nome de segunda pele. A autora traz a noção de pele psíquica sendo uma função primária em sua forma mais primitiva antevendo o desenvolvimento psíquico do bebê, isto é, introjeção continente e criação da pele psíquica concluindo uma imagem mental (boca-seio).

Ainda de acordo com Bick (1988) "O objeto continente é experimentado [pelo bebê] concretamente como uma pele [...] " (p.56). Sem essa 'pele' que a mãe representa, o bebê seria assolado por terríveis ansiedades e medo de se desmantelar, derramar-se (life-spillingout), derreter-se (liquefying).

Então, o 'objeto ótimo' para promoção da experiência de contenção, seria “[...] o mamilo na boca, juntamente com a mãe que segura o bebê, fala com ele e tem um cheiro familiar." (p. 56). Este contato corporal/sensorial do bebê com a mãe, proporciona a este a experiência de estar envolvido por uma pele, de estar contido, que torna possível o surgimento da noção de um espaço dentro do self e posterior cisão primária onde o bebê se vê como parte separada do objeto mãe (Bick, 1988).

Sem espaços internos nos quais possa projetar (identificação projetiva), surge no indivíduo o fenômeno de 'aderir' a objetos por meio de uma identificação adesiva, que ocorre por um lapso na distinção entre o espaço interno e externo, levando à criação de um distúrbio de caráter, onde tudo passa a ser superficial, imitativo.

Mais voltada à prática clínica, Bick, baseada na rêverie materna de Bion, onde a mãe é capaz de modificar o que o bebê Ihe Introjeta, transformando o elemento Beta em Alfa (função alfa), propôs que o observador da mesma forma, poderia receber os elementos beta e também ser capaz de transformá-los, (sendo ele próprio contingente) propiciando a mudança emocional e oferecendo a possibilidade de aprendizado por parte de conseguir o rêverie (Mélega, 1998).

O método pode funcionar também como meio de investigação psicanalítica. Baseados nisso, recentemente, alguns autores têm sugerido aplicar o método à clínica e/ou à investigação psicanalítica, buscando um diálogo do método com a pesquisa científica.

O método é constituído por três momentos: observação, relato da observação e leitura e discussão em supervisão coletiva. O primeiro momento se dá com as observações semanais com uma hora de duração por dois anos, sempre na mesma hora e lugar (Bick, 
[1964] 2002; Rustin, 1997, 2003). No segundo momento, geram-se relatos escritos do que foi observado (Rustin, 1997, 2003). Sobre o registro da observação, este deve ser fortuito, casual, mas representativo daquilo que o observador conseguiu editar. No terceiro momento, a leitura e discussão do relato com supervisão baseada nos pressupostos da técnica psicanalítica, tendo-se como ponto central, o bebê, seu ambiente e o observador. O processo é supervisionado por um psicanalista clínico experiente (Mélega, 1995, 1997; Rustin, 2006; Souza, 1995).

\section{O MÉTODO NO BRASIL}

É um método considerado ainda pouco conhecido no Brasil, o que demanda mais estudos para o uso prático, possibilitando que as etapas definidas por Bick (1964) tenham maior alcance. Segundo estudiosos do assunto no Brasil, Santos e Pedroso, (2017) são necessárias adaptações que podem vir a trazer crescente interesse de pesquisadores de Psicologia e áreas afins em trabalhar com desenvolvimento humano levando-se em consideração o contexto social no qual os participantes de pesquisas estão inseridos.

Não apenas a aplicação clínica deve ser vista, bem como mais estudos são necessários dentro das situações tipicamente brasileiras como as de vulnerabilidade social.

No aspecto clínico, Marisa Pelella Mélega, psicanalista brasileira e diretora do Centro de Estudos Psicanalíticos Mãe-Bebê-Família em São Paulo - que utiliza a observação e método de Intervenções Terapêuticas Conjuntas pais-filhos, como modalidade a ser aplicada com fins de avaliação diagnóstica - fala sobre o método de observação de Bick:

Ao usarmos o termo aplicação do Modelo de Bick, estamos nos referindo ao trabalho clínico que privilegia um conjunto de atitudes de mente para observar: ser receptivo, estar no clima emocional do objeto de observação, lidar com as próprias emoções despertadas pela função de observar e não intervir ativamente no objeto de observação (Mélega, 2008, p. 269).

Para Mélega, Bick levou a psicanálise para dentro do lar. Defensora da função contingente da observação, ela fala sobre a observação da relação mãe-bebê que propicia, em suas palavras "acompanhar alguns momentos da intimidade de uma relação mãe-criança e de estudar o que se passa no trajeto entre a emoção e a produção da imagem onírica representação da emoção (Mélega, 2009). 
A observação permite aproximar-se da 'área de mistério' onde atua a função Alfa função primária da mãe. Analisar e intervir (Sá, 2009).

Em trabalho contínuo na busca de um meio de tratar-se a criança em sofrimento psíquico, Mélega (1998) propõe a técnica de Intervenções Terapêuticas conjuntas pais-Filhos, como modalidade a ser aplicada para uma avaliação diagnóstica que trouxesse bons resultados. Para Mélega (1997), a observação aliada à realização de intervenções psicoterápicas conjuntas pais-crianças, é uma técnica eficaz para diagnosticar com a participação familiar quadros infantis de grave perturbação emocional promovendo a comunicação e compreensão entre os participantes.

O trabalho de Mélega abriu caminho para um significativo trabalho de psicanalistas interessados em intervir conjuntamente pais e filhos, hoje temos artigos e dissertações que abordam o tema e trazem a experiência clínica do trabalho conjunto. No presente trabalho apenas citamos essas contribuições e ressaltamos que são leituras que enriquecem a pratica clínica (Marra, 2005; Quagliatto, Cunha; Chaves; Pajola; Lemgruber (2008).

\section{CONSIDERAÇÕES FINAIS}

As relações afetivas primárias segundo os autores estudados, se constituem no alicerce fundamental onde se estrutura a mente humana. Sendo estas de fundamental importância para a psicanálise. Apesar de diferenças na abordagem e se cada autor segue ou não a linha freudiana, há um consenso entre estes de que os anos iniciais e a relação do bebê com sua mãe são fundamentais para a constituição do aparelho psíquico do indivíduo.

Segundo os autores estudados, é fundamental conhecer e reconhecer a importância do conjunto de experiências clínicas que propiciam maior entendimento dos processos na vinculação mãe e bebê. Conhecer e reconhecer suas contribuições é fundamental para a compreensão e estudo da relação da díade.

O trabalho de Esther Bick é de fundamental relevância no que concerne ao entendimento e intervenção da relação mãe-bebê. Consideramos, após o caminho teórico aqui apresentado, que seu método oferece uma observação viva e genuína da relação da mãe e seu bebê dentro do lar. E, além disso, proporcionou diversas possibilidades de atuação e intervenção com mães e bebês em estado de sofrimento psíquico (ressaltamos as contribuições de Mélega e seus seguidores no Brasil). Acreditamos que muito ainda pode ser explorado e desenvolvido no que se refere a aproveitar mais as contribuições de grandes psicanalistas como Bick. 
A conclusão possível após os enunciados é que o método de observação da relação mãe-bebê é um meio de se observar de maneira genuína a relação da díade em ambiente doméstico, possibilitando a percepção da presença/ausência de rêverie, as falhas e a intervenção para o bem psíquico dos envolvidos.

\section{REFERÊNCIAS}

Bick, E. (1988) A experiência da pele em relações de objeto arcaicos. in: Spillius E., Melanie Klein hoje. Rio de Janeiro: Imago.

Bion, W. R. (1994) Estudos psicanalíticos revisados. (3ª ed.) Rio de Janeiro, Imago.

Bowlby, J. (2001) Formação e rompimento dos laços afetivos. Trad. Álvaro Cabral. São Paulo: Martins Fontes.

Coutinho, F. (1997) O ambiente facilitador: a mãe suficientemente boa. In: Winnicott - 100 anos de um analista criativo. Rio de Janeiro: Nau.

Feliciano, D S. (2009) Para além do seio: uma proposta de intervenção psicanalítica pais-bebês, a partir da escuta dos sentimentos ocultos nas dificuldades de amamentação, como auxiliar no desenvolvimento. Tese de Doutorado Universidade São Paulo; São Paulo, Brasil.

Freud, S. (1974) Fragments of an Analysis of a case of Hysteria (1905 [1901]), Vol. (VII) London: the hogarth press.

, (1938) Esboço de Psicanálise. In: Edição Standard Brasileira das Obras Psicológicas completas de Sigmund Freud Rio de Janeiro: (vol. 23 p. 202). Imago.

Hinshelwood, R. D. (1992) Dicionário do pensamento kleiniano. Porto Alegre. Artmed.

Klein, M. (1996) O Desmame. In: Klein, M. Amor Culpa e Reparação. (pp 330-343) Rio de Janeiro: Imago.

. (1952) As origens da transferência. In Klein, M. Inveja e gratidão e outros trabalhos (1946-1963) (L. P. Chaves, Trad. pp. 71-80). Rio de Janeiro. Imago.

. (1996) A importância da formação de símbolos no desenvolvimento do ego, 1930; Rio de Janeiro: vol. (1) Imago.

Marra, R. A. S. (2005) Atendimento psicoterapêutico conjunto pais-crianças em serviço ambulatorial. Dissertação (Pós-Graduação em Psicologia) - Universidade Federal de Uberlândia, Uberlândia, Minas Gerais, Brasil.

Martins, H. H. T. S. (2004) Metodologia qualitativa de pesquisa. Educ. Pesqui. Mélega, M. P. Intervenções terapêuticas conjuntas Pais-Filhos. Alter - Jornal e Estudos Psicodinâmicos. 30 (2). São Paulo. 
- (1997) Vínculo k (knowledge) e o desenvolvimento da Capacidade simbólica. Modificação do trabalho apresentado durante o International Centennial Conference on the Workof W.R.Bion, Turin/Itália.

. (2017) Imagens oníricas e suas representações. Sociedade Brasileira de Psicanálise de São Paulo. Ide (São Paulo) v.32 (49) pp. 99 - 105

Menegotto, L. M. O., Lopes, R. C. S. Caron, N. A. (2010) O método Bick de observação da relação mãe-bebê: Aspectos clínicos. Psic.clin., 22 (1) pp. 39 - 55.

Monroe, P. (1946) História da Educação. Rio de Janeiro: Companhia Editora Nacional.

Neves, FJ L. (2007) A psicanálise Kleiniana. Reverso 29 (54) pp. 21 - 28

Parsons, M. (2007). Sobre a rêverie. Rêverie: Revista de Psicanálise, 1 (1)

Quagliatto, H.; Cunha, M. F.; Chaves, L. S.; Pajola, L. G.; Lemgruber, K. (2008) Evoluções e revoluções na clínica psicanalítica infantil: da orientação aos pais à avaliação-intervenção conjunta pais-filhos. Artigo científico in Contextos Clínicos. 1, (1) pp. 43 - 48.

Sá, M T C. (2009) Angústias precoces, rêverie materna, destinos da Violência. Interações 13, pp. $338-352$.

Santos, C. S. P. R. (2014) A intersubjectividade na relação continente-conteúdo através de um Rorschach de aplicação conjunta mãe adoptiva e filha adoptada. Tese de Mestrado Instituto Superior de Psicologia Aplicada. Lisboa, Portugal

Winnicott, D. W. (1990) O ambiente e os processos de maturação: estudos sobre a teoria do desenvolvimento emocional. Porto Alegre, Artes Médicas.

. (2000). Da Pediatria à Psicanálise: Obras Escolhidas. Rio de Janeiro: Imago

- (2001). Objetos e fenômenos transicionais. In: D.W. Winnicott, Da pediatria à psicanálise: obras escolhidas. (D. Bogomoletz, trad. pp. 316 - 331). Rio de Janeiro: Imago.

. (1994). Sobre as bases do self no corpo. In: C. Winnicott, R. Shepherd \& M. Davis (Orgs.). Explorações psicanalíticas D. W. Winnicott. (J. O. A. Abreu, trad. pp. 203 - 218). Porto Alegre: Artmed.

(2000) Preocupação materna primária. In: D. W. Winnicott: da pediatria à psicanálise. Rio de Janeiro: Imago. 